Kristian Emil Kristoffersen. Speech and language development in cri du chat syndrome: a critical review. Clinical Linguistics \& Phonetics 2008, vol 22(6), pages 443-457

This is an author produced version of the article. The original publication is available at Informaworld

http://www.informaworld.com/openurl?

genre $=$ article\&issn $=0269 \% 2 \mathrm{~d} 9206 \&$ volume $=22 \&$ issue $=6 \&$ spage $=443$

Access to the published version may require journal subscription.

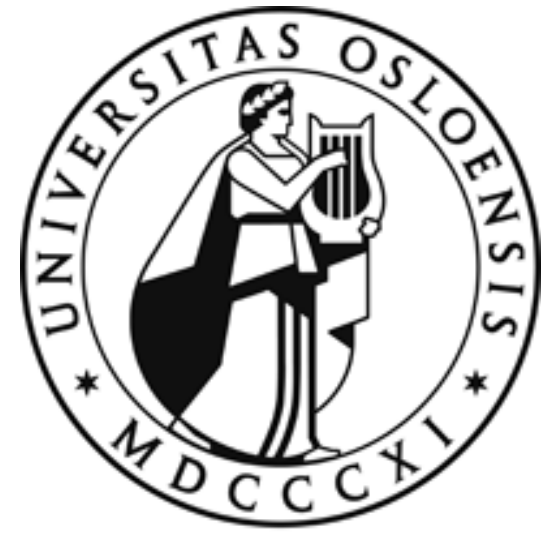




\section{Speech and language development in cri du chat syndrome - a critical review}

Kristian Emil Kristoffersen

Department of Linguistics and Scandinavian Studies,

University of Oslo, Norway

P.O. Box 1102 Blindern,

$\mathrm{N}-0317$ Oslo

E-mail:k.e.kristoffersen@iln.uio.no

Fax: +4722857100 


\title{
Speech and language development in cri du chat syndrome - a critical review
}

\author{
KRISTIAN EMIL KRISTOFFERSEN \\ Department of Linguistics and Scandinavian Studies, University of Oslo, Norway
}

\begin{abstract}
This article reviews research on speech and language abilities in persons with cri du chat syndrome (CCS). CCS is a rare genetic disorder resulting from a deletion of genetic material on the short arm of chromosome 5 with an estimated incidence between 1 in 15000 births and 1 in 50000 births. In general, individuals suffering from CCS have delayed speech and language development, and not all of them develop spoken language at all. Their receptive language has been found to be better than their expressive language, even though both are delayed. In the domain of phonetics and phonology, substitutions, omissions, and distortions are frequent, consonant inventories are small, syllable shapes are restricted, and vowels are variable and overlap with each other acoustically. Persons with CCS have been found to inflect words from all major word classes. Little is known about syntactic skills, but some individuals are reported to express themselves in utterances of two or more words. In spite of these findings, knowlegde about speech and language development in CCS is sparse, and the need for more research is considerable.
\end{abstract}

Keywords: Cri du chat syndrome; speech development; language development

\section{Introduction}

Cri du chat syndrome (CCS), also known as $5 \mathrm{p}$ - syndrome, is a rare genetic disorder with an estimated incidence between 1 in 15000 births (Higurashi, Oda, Iijima, Iijima, Takeshita, Watanabe, \& Woneyama, 1990; Medina, Mariescu, Overhauser, \& Kosik, 2000) and 1 in 50000 births (Niebuhr, 1978; Wu, Niebuhr, Yang, \& Hansen, 2005). The syndrome was first described by Lejeune, Lafourcade, Berger, Vialette, Boeswillwald, Serginge, \& Turpin (1963), and is associated with a deletion on the short arm of chromosome 5. The size of the deletion ranges from the entire short arm to the region 5p15.3 (Overhauser, Huang, Gersh, Wilson, McMahon, Bengtsson, Rojas, Meyer, \& Wasmuth 1994; Simmons, Goodart, Gallardo, Overhauser, \& Lovett 1995). In about 90 
$\%$ of the cases the deletion is de novo, in the remaining cases it results from parental balanced translocations (Laczmanska, Stembalska, Gil, Czemarmazowicz, \& Sasiadek 2006).

Clinical features vary considerably from patient to patient, but typically include a high-pitched cry in infancy and childhood (Sparks \& Hutchinson, 1980; Sohner \& Mitchell, 1991), and distinct facial dysmorphism. Furthermore, malocclusion, hyper- and hypotonia, and delayed motor development is common (Carlin, 1990), as well as microcephaly (Niebuhr, 1978). Patients with CCS also show various degrees of intellectual disability. Cornish, Bramble, Munir, \& Pigram (1999) showed in a study of 26 UK children with CCS that full-scale IQ, as measured by the Wechsler Intelligence Scale for Children (WISC-III) (Wechsler, 1992), varied from below 40 (four children) to between 40 and 57 (mean 47.81) (the remaining children). Individuals with CCS have also been shown to have short attention span, hyperactivity, and stereotyped, aggressive and self-injurious behaviour (Collins \& Cornish, 2002), as well as speech and language deficits (Cornish \& Munir, 1998; Cornish \& al, 1999; Kristoffersen, 2004; 2005; 2007b).

In recent years our knowlegde of how genetic factors contribute to language development has expanded, as a result of an increasing number of studies of linguistic development in various genetic disorders, e.g. dyslexia, autism and SLI (see Smith, 2007, for a recent review). As has been pointed out by Warren \& Abbeduti (2007) that an important theoretical contribution of these studies is to replace the earlier dichotomy of "nature versus nurture" with more refined models where both genetic, neurological and environmental factors are involved. Furthermore, in a clinicial perspective, studies linguistic deficits associated with genetic disorders are important because they provide speech and language therapists with a more solid basis for developing diagnosis and treatment procedures for indviduals suffering from such disorders.

Today there is a growing body of research into language deficits associated with genetic disorders like Down syndrome (see Roberts, Price \& Malkin, 2007 for a recent review), Williams syndrome (see Brock, 2007; Mervis \& Becerra, 2007), and fragile X syndrome (see Abbeduto, Brady, \& Kover, 2007). On the other hand, little is known about speech and language abilities and development in CCS. Therefore, the primary aim of this paper is to review the few studies that report on language abilities in individuals 
with this syndrome along with studies within other fields noting language abilities in passing. The article will also examine the implications of these findings for clinical linguistics and for linguistic theory.

The article is organized in seven main sections, covering (1) general communication skills, (2) the relationship between receptive and expressive language, (3) babbling and first words, (4) vocabulary, (5) phonetics and phonology, and (6) morphology and syntax. The final section summarizes the article.

\section{Communication skills}

Already during their first months of life typically developing infants show signs of communcative behaviour, and from about their first birthday they start using their first words. Around the age of five they have acquired the basic skills necessary to comunicate efficiently by means of spoken language. In comparison, general communication skills are delayed in individuals with CCS. However, there is much variation from one person to the next: Among children with this syndrome who are older than five years of age we find some who appear not to communicate at all. Others communicate only by signs or by alternative augmentative techniques. And there are some who sommunicate by spoken language, but usually only with one-word utterances, or by short multi-word utterances. It is reasonable to assume that both genetic and environmental factors play a role in determining the extent of the delay. However, only future research can resolve this issue.

A few studies have examined general conunication skills in personons with CCS. Wilkins, Brown, \& Wolf (1980) investigated psychomotor development in 65 homereared US children with this syndrome (mean chronological age males: 8 years; mean chronological age females: 6;2; age range: $0 ; 2-26$ years), and found that only $50 \%$ were able to use language 'to express needs and emotions'. Similarly, Carlin (1990), reporting from a study of 62 US individuals with CCS (age range: newborn - 34 years), noted that speech had developed in $50 \%$ of the subjects while $75 \%$ of them used signing or other communication methods. Neither of these two studies explicate the notions "language" and "speech" in any details. In other words, they provide no information that can be used in developing diagnosis and treatment procedures. 
Cornish \& Pigram (1996) examined behavioural characteristics in a population of 27 indivudals (mean chronological age: 8;3; age range 4;0-16;0) with CCS in the UK. Their chronological age ranged from $4 ; 0$ to $16 ; 0$, with a mean of $8 ; 3$. No information about their non-verbal mental age or overall IQ range is given. Developmental and behavioural characteristics were assessed by means of a parental questionnaire (Society for the Study of Behavioural Phenotypes questionnaire), where the ability to communicate was determined on the basis of how the subjects made their needs known. The study showed that $25.9 \%$ used speech for this purpose, whereas $7.4 \%$ used a formal sign or symbol system. Furthermore, $48.1 \%$ of the subjects communicated their needs by means of 'non-verbal method', whereas $18.5 \%$ did not indicate needs at all. Again it is the case that the notion of "speech" is not explicated in any way.

Baird, Campbell, Ingram, \& Gomez (2001) investigated developmental and behavioral patterns in 13 young children (mean chronological age 2; 4 . Age range 0;11 $3 ; 11)$ in the US. Information was obtained by means of the Developmental Observation Checklist Profile of the Developmental Observation Checklist system (DC-DOCS) (Hresko et al., 1994), a standardized, norm-referenced instrument where caregivers report on motor, cognitive, communicative and social development. In the language domain four of the children were found to have less than a $25 \%$ developmental delay on a comparison of their chronological ages and their age equivalents obtained from the DCDOCS. Six had a delay between 25 and $49 \%$, whereas three had more than $50 \%$ delay. Only three of the children used spoken language for communication. The parents reported that in these cases spoken language was used effectively. This study also noted minimal variation across developmental domains.

Cornish, Bramble, Munir, and Pigram (1999) assessed the cognitive functioning in 26 UK children with CCS (mean age 8;3. Age range: 6;4-15;5), using the Wechsler Intelligence Scale for Children (WISC-III) (Wechsler, 1992), BPVS, TROG, the Goldman-Fristoe Test of Articulation (GFTA) (Goldman \& Fristoe, 1986), the Expressive One Word Picture Vocabulary Test-Revised (EOWPVT-R) (Gardner, 1990), and the expressive language section of RLDS. They found that 21 of the children had a full-scale IQ (as measured by WISC-III) below 50, whereas the remaining five children fell into the range between 51 and 60. Furthermore, 14 children had a verbal IQ below 50, whereas 
the verbal IQ of the remaining 10 ranged from 51 to 64 . When performance on the individual subtests of the WISC-III was compared, no significant patterns of strength and weaknesses was found. However, a significant negative correlation $(\mathrm{r}=0.408 ; \mathrm{P}<0.038)$ between verbal IQ and chronological age was found.

The studies reviewed in this section indicate that persons with CCS have limited commmunication skills. Also, communication skills appear to vary from one individual to the next: not all of them develop spoken language, and when they do, their language skills vary considerably. In some cases sign language is also used successfully. Several questions, however, remain to be answered. First of all, it is unknown how much of this variation can be attributed to the syndrome, and how much to envorionmental factors. A further question arising from these studies is to what extent language development in CCS is delayed and to what extent it is also atypical.

\section{Receptive vs expressive language}

In typically developing children there is an asymmetry between receptive and expressive language. For example, from about eight months infants appear to understand some words, whereas their first words in production appear some months later, typically around their first birthday. A considerable difference between receptive and expressive language has also been noted in persons with CCS. Schlegel, Neu, Carneiro Leão, Reiss, Nolan, \& Gardner (1967) examined the case of a girl aged 10;3, whose receptive language abilities were reported to be at about 3-year level. At the same time her expressive language was found to be echolaic, and she used 'actual words, not jargon, for pleasure, and to communicate', facts which point towards far better receptive than expressive language abilities.

Some twenty years later, Cornish \& Munir (1998) studied receptive and expressive language skills in 13 UK children with CCS (mean chronological age 8;10; age range 4 -14). Their comprehension of vocabulary was measured by the British Picture Vocabulary Scales (BPVS) (Dunn, Dunn, Whetton, \& Pintilie, 1982), their comprehension of grammar was measured by the Test of the reception of grammar (TROG) (Bishop, 1983), and their expressive language abilities were measured by the 
Reynell Language Development Scales (RLDS) (Reynell, 1985). A discrepancy was found between these children's chronological age and their linguistic age, a discrepancy which increased as the chronological age increased. Also, a discrepancy was found between receptive and expressive language skills, in that language comprehension (as measured by BPVS and TROG) was significantly better than language production (as measured by RLDS), cf. table 1.

Table 1. Language skills in 13 UK children (mean chronological age 8;10; age range 4 - 14) with CCS (Cornish \& Munir, 1998)

\begin{tabular}{llc}
\hline & Mean & Range \\
\hline British Picture Vocabulary Scales (10 children) & 4.3 years & $2-12.2$ years \\
Test for the Reception of Grammar (10 children) & 4.1 years & $4-11$ years \\
Reynell Language Development Scales (13 children) & 1.5 years & $1-7$ years \\
\hline
\end{tabular}

Cornish and Munir note that whereas receptive skills, with a mean score of 4.1/4.3 years appear to increase slightly from about the age of 10 years, expressive skills remained low relative to chronological age (the majority of children never got beyond an age equivalent of 2.3 years). Thus, the asymmetry between receptive and expressive language must be said to deviate clearly from what is expected for normal development at this stage of development.

The findings of Cornish \& al (1999) (see above for a detailed presentation) corroborate the findings of the study by Cornish and Munir, cf. table 2.

Table 2. Language skills in 26 UK children (mean age 8;3. Age range: 6;4-15;5) with CCS (Cornish \& al., 1999)

\begin{tabular}{llc}
\hline & Mean & Range \\
\hline British Picture Vocabulary Scales (23 children) & 4.38 years & $2-7$ years \\
Test for the Reception of Grammar (19 children) & 4.85 years & $4-6$ years \\
Reynell Language Development Scales (24 children) & 1.75 years & $1-5$ years \\
Expressive One Word Picture Vocabulary Test - Revised (11 children) & 2.7 years & $2-5$ years \\
\hline
\end{tabular}


In sum, the children examined by Cornish and her colleagues had receptive language skills between 4 and 5 years of age, and expressive skills between 1.5 and 2.7 years, i.e., clearly deviant as compared to these skills in typically developing children.

A possible weakness of these studies, however, is that the authors do not make it clear whether the children in the study by Cornish \& Munir (1998) are among the children who participated in the more recent study. Furthermore, it is not without problems to interpret mean scores collapsed over such wide ranges. A third shortcoming of these findings is that the expressive and receptive skills are only described in general terms. Thus, one may for example ask whether all aspects of expressive skills are equally delayed, or whether persons with CCS fare better in some expressive skills than in others. In the next sections, studies which may throw some light on this question will be reviewed.

\section{Babbling and first words}

In typically developing children a prolonged period of babbling in the second half of the first year precedes the appearance of first words at around the first birthday. Also in this domain persons with CCS are delayed. In a longitudinal study of one child through the ages 8-26 months, Sohner \& Mitchell (1991) found that babbling did not appear until 13 months. In comparison, absence of canonical babbling at the age of 10 months is considered a possible marker of abnormal development (Oller \& al. 1998)

Concerning the appearance of first words, Silber, Engel, \& Merril (1966) described a 7 year-old girl whose first word appeared at the age of two. Furthermore, Mainardi \& al. (2000) reported from a questionnaire-based study of 84 Italian individuals with CCS (age range 0;9-34 years; median 7;9). For 66 of these the appearance of first words were reported: by 19 months of age, $25 \%$ of them had uttered their first words, by three years the share was $50 \%$, by four years $75 \%$ and by eight years $95 \%$. It is an open question, however, to what extent parental report data on the appearance of first words for adults and older children are reliable. Thus, the need for for further research here is obvious. 


\section{Vocabulary}

Due to the adaptation of the MacArthur Communication Development Invetory (Fenson, Dale, Reznick, Thal, Bates, \& Hartung (1993) into a number of languages, we have extensive knowledge of lexical development both in typically developing children, and also in some populations with language disorders (Singer-Harris, Bellugi, Bates, Jones, and Rossen (1997), Mervis \& Robinson (2000), Vicari, Caselli, Gagliardi, Tonucci, \& Volterra (2002).

On the other hand, no systematic studies of vocabulary size in persons with CCS have been conducted to date. Once again, however, some sporadic observations are reported in the literature. Sparks \& Hutchinson (1980) described the case of a girl who according to her mother had a receptive vocabulary of 6-12 words at nine months. At the age of 2;7 her speech therapist reported her to have an expressive vocabulary of five words. Wilkins \& al. (1980) reported that 11 of their subjects (eight of whom were older than 10 years) had vocabularies of more than 100 words. ${ }^{1}$ Also in this case, however, one may ask to what extent parental report data are reliable.

In a study of receptive vocabulary in the domain of verbs, Wium (2006) measured the ability to comprehend lexical verbs in three Norwegian subjects (aged 11, 15 and 22) with CCS by means of a subtest included in VOST battery (Bastiansee, R., Lind, M., Moen, I., \& Simonsen, H. G., 2006), a Norwegian version of the Dutch VEZT battery. This particular subtest evaluates auditory comprehension of 40 verbs varying in transitivity, word frequency and name relatedness with a noun. Of the 40 verbs, the three subjects had 34 (subject aged 11), 32 (subject aged 15), and 36 (subject aged 22) correct responses. In other words, all three showed good understanding of lexical verbs in Norwegian.

Also in the area of lexical skills and development, we see that the few studies that exist leave a number of questions unanswered: First, to what extent is development of comprehensive vocabulary in CCS comparable to that of typically developing children, and children with other disorders? Second, since comprehension of verbs appear to be relatively good, is this also the case with other lexical categories? A furher question is to

\footnotetext{
${ }^{1}$ Although this is not stated explicitly, its seems reasonable to assume that what is meant here is expressive and not receptive vocabulary.
} 
what extent individuals with CCS comprehend function words? Finally, one can ask to what extent receptive vocabulary is in line with conceptual development (as it is, say, in low functioning children with autism) or in advance of conceptual development (as it is, say, in Williams syndrome).

\section{Phonetics and phonology}

In the domain of phonetics and phonology early observations were few, and mostly general remarks about misarticulations. A couple of studies have also focused on the high-pitched voice in children with CCS. In recent years, however, a small number of studies have appeared on phonetic and phonological skills of Norwegian children with CCS. As a result we now have some more specific knowledge about types of misarticulations, as well as about consonant and vowel inventories and syllable shapes.

\section{High fundamental frequency}

Perhaps the most salient characteristic of young children with CCS is their high-pitched voice. Sparks \& Hutchinson (1980) measured the mean fundamental frequency in their subject at the age of 7;6 to $520 \mathrm{~Hz}$, as compared to a reported value of $273 \mathrm{~Hz}^{2}$ for typically developing 7-year-old girls.

Sohner \& Mitchell (1991) reported that their subject had an average fundamental frequency of $585.38 \mathrm{~Hz}$ betweeen 11 and 26 months, as compared to an average of 357 $\mathrm{Hz}$ (range $=164-1366$ ) in a group of typicially developing children between 11 and 25 months reported by Robb \& Saxman (1985). In other words, the fundamental frequency reported by Sohner \& Mitchell (1991) lies within the range of variation of typically developing children the same age as their subject.

In handbooks directed at parents and other caregivers it is often said that the highpitched cry may disappear with age (see e.g. Cornish, Bramble, \& Collins, 1998). However, there are no published data on this issue.

2 The authors do not give any infomation on the range of variation. However, Lee, Potamianos, and Narayanan (1999) found in a study of the acoustic properties of US children's speech that the mean value of the fundamental frequency in 7-year-old girls were $272 \mathrm{~Hz}$, measured on the basis of 14 tokens. Standard deviation was reported to be 37. 
Misarticulations: substitutions, distortions, and omissions

Schlegel \& al., (1967) and Sparks \& Hutchinson (1980) noted that their subjects had a lot of substitutions and omissions in their speech, and Cornish \& al (1999) reported that misarticulations were very frequent among their 26 subjects, all of them being below the 10th centile for their age range. Neither of these three studies explicated the exact nature of these misarticulations.

Kristoffersen (2003b) examined substitutions and omissions in his daughter Hanna's words at ages 5;9 and 7;0. Table 3 names and illustrates the processes that were identified.

Table 3. Omissions and substitutions in the speech of one girl with CCS (Kristoffersen 2003b)

\begin{tabular}{|c|c|c|}
\hline Omissions (at 5;9) & Stopping (at $7 ; 0)$ & Cluster reductions $(5 ; 9$ and $7 ; 0)$ \\
\hline $\begin{array}{ll}\text { - } & \text { [i] for /şi:/ ski 'ski' and is } \\
& / \mathrm{i}: \mathrm{s} / \text { 'ice' } \\
\text { - } & {[\mathrm{u}] \text { for /ju:s/ jus 'juice' }} \\
\text { - } & {[æ k] \text { for /çeks/ 'biscuit' }}\end{array}$ & $\begin{array}{ll}\text { - } & {[\mathrm{it}] \text { for } / \mathrm{i}: \mathrm{s} / \text { is 'ice' }} \\
\text { - } & {[\mathrm{uk}] \text { for } / \mathrm{dus} / d u s j \text { 'shower' }}\end{array}$ & $\begin{array}{ll}\text { - } & \text { ['patæ] for /'spa:də/ spade } \\
\text { 'shovel' (5;9) } \\
\text { - } \quad \text { ['pilæ] for /'brilf/ briller } \\
\text { 'glasses' }(5 ; 9) \\
\text { - } \quad \text { ['milæ] for /'smi:lə/ smile } \\
\text { 'smile' (7;0) } \\
\text { - } \quad \text { [po] for [blo:/ blå 'blue' }\end{array}$ \\
\hline
\end{tabular}

Some of the misarticulations listed in table 3 are also common in the speech of young typically developing children. However, the examples of word-initial omissions illustrate a process which is relatively rare among typically developing children (Small, 2005), indicating that at least as far as omissions are concerned language development in CCS is deviant.

\section{Consonants}

Kristoffersen (2003a and b) was a longitudinal case study of his daughter Hanna with particular focus on her development of consonant inventories, syllable structures and phonological processes. Her consonant inventories at three different ages - 4;6, 5;9 and 7;0 - are shown in table 4. 
Table 4. Consonant inventories of one Norwegian girl with CCS (Kristoffersen 2003a)

\begin{tabular}{|c|c|c|c|c|c|c|c|c|c|c|c|}
\hline \multicolumn{4}{|c|}{$4 ; 6$} & \multicolumn{4}{|c|}{$5 ; 9$} & \multicolumn{4}{|c|}{$7 ; 0$} \\
\hline Lab & Cor & Dor & Glo & $\mathrm{Lab}$ & Cor & Dor & Glo & $\mathrm{Lab}$ & Cor & Dor & Glo \\
\hline $\mathrm{p}$ & & $\mathrm{k}$ & & $\mathrm{p},\left(\mathrm{p}^{\mathrm{m}}\right)^{*}$ & $\mathrm{t}, \mathrm{t}\left(\mathrm{t}^{\mathrm{n}}\right)$ & $\mathrm{k}$ & & $\mathrm{p}$ & $t, \mathrm{t}$ & $\mathrm{k},\left(\mathrm{k}^{\mathrm{n}}\right)$ & \\
\hline $\mathrm{m}$ & $\mathrm{n}$ & $\eta$ & & $\mathrm{m}$ & $\mathrm{n}$ & $y$ & & $\mathrm{~m}$ & $\mathrm{n}$ & $y$ & \\
\hline & & & $\mathrm{h}$ & & & & $\mathrm{h}$ & & $\theta$ & & $\mathrm{h}$ \\
\hline (v) & $1,(1)$ & $\mathrm{j}$ & & & 1 & $\mathrm{j}$ & & (v) & 1 & $\mathrm{j}$ & \\
\hline & & & $?$ & & & & $?$ & & & & $?$ \\
\hline
\end{tabular}

*Phonetic symbols in parentheses represent marginal phones, i.e. sounds which occur only once or twice in the material (cf. Grunwell 1985, 31).

Typically developing children learning Norwegian master the majority of Norwegian consonant phones by their third birthday, the exceptions being /s, $r, 1, \mathrm{~d}, \mathrm{r}, \mathrm{c}, \mathrm{j} /$ (cf. Kristoffersen (2007a) for a review of acquisition of consonants in typically developing Norwegian children). Thus, as table 4 clearly shows, Hanna had far fewer consonants than typically developing Norwegian children. She also had some deviant consonants. First, there were plosives with nasal release at all three points of observation, suggesting a problem with velopharyngeal function. Second, she had a linguolabial plosive at 5;9 and 7;0, indicating lack of control of tongue movement. Finally, she made no distinction between voiced and voiceless plosives, suggesting poor control of laryngeal setting.

These findings were corroborated by a study of the consonant inventories of three additional Norwegian children with CCS (Kristoffersen, 2004). Their inventories are displayed in table 5 .

\begin{tabular}{|c|c|c|c|c|c|c|c|c|c|c|c|}
\hline \multicolumn{4}{|c|}{ Girl aged 10;8 } & \multicolumn{4}{|c|}{ Boy aged 9;2 } & \multicolumn{4}{|c|}{ Boy aged 10;0 } \\
\hline $\mathrm{Lab}$ & Cor & Dor & Glo & $\mathrm{Lab}$ & Cor & Dor & Glo & $\mathrm{Lab}$ & Cor & Dor & Glo \\
\hline $\mathrm{p}, \mathrm{b},{ }^{\mathrm{m}} \mathrm{b}$ & $\mathrm{t}, \mathrm{t}^{1}, \mathrm{~d},{ }^{\mathrm{n}} \mathrm{t}$ & $\mathrm{c}^{1}$ & \multirow{5}{*}{$\mathrm{h}$} & $\mathrm{p},{ }^{\mathrm{m}} \mathrm{b}$ & $(\mathrm{t}),{ }^{\mathrm{n}} \mathrm{d}$ & $\mathrm{k},{ }^{\mathrm{n}} \mathrm{g}$ & & $\mathrm{p}$ & \multirow{2}{*}{\multicolumn{3}{|c|}{ (y) }} \\
\hline $\mathrm{m}$ & $\mathrm{n}$ & (n) & & $\mathrm{m}$ & (n) & $\mathrm{y}$ & & & & & \\
\hline $\mathrm{f}$ & $\mathrm{s}, \ddot{\theta}$ & & & (f) & & (ç) & & & $\theta$ & & $\mathrm{h}$ \\
\hline$v$ & 1 & $\mathrm{j}$ & & & & & & (w) & (1) & (j) & \\
\hline & & & & & & & $?$ & & & & $?$ \\
\hline
\end{tabular}


The inventories in table 5 are all small as compared to the inventories of typically developing children. In addition, they show the individual variation noted in previous research - the girl has a relatively large inventory, whereas the boy aged 10 has a very small inventory, in fact only four consonants $/ \mathrm{p}, \theta, \mathrm{h}, \mathrm{\imath} /$ are non-marginal. In other words, all lingual consonants are marginal. These findings may indicate inadequate lingual control.

Two of the children whose inventories are displayed in table 5 also show signs of problems with the velopharyngeal function. Both the girl and the boy aged 9;2 have prenasalized stops. The girl examined in this study also had some articulations - lingual stops with lateral release - which may be taken to indicate less than adequate control of the muscles controlling the tongue. These facts also fit well with results from other studies showing a general problem with fine motor control associated with CCS.

Kristoffersen (2007b) was a longitudinal study of the development of error rates and error patterns in the consonant productions of Hanna from she was 4;6 til she was $9 ; 4$. Error rates were measured at four points of observation $(4 ; 6,5 ; 9,7 ; 0$ and 9;4) in terms of Percent Consonants Correct (PCC; Shriberg \& Kwiatowsky, 1982; Shriberg, Austin, Lewis, McSweeny, \& Wilson, 1997) and Percent Consonant Clusters correct (PCCC; Smit, 1993; MacLeod, van Doorn, \& Reed, 2001) and were found to be high at all four ages. The PCC varied from $22.8 \%$ at $4 ; 6$ to $69 \%$ at $9 ; 4$. As no studies measuring PCC in typically developing children and children with other speech and language disorders than CCS learning Norwegian exist, it is difficulot to compare Hanna's performance with that of other groups in the same language. However, in a study of children learning Swedish, a Germanic language closely related to Norwegian. Hansson \& Nettelbladt (2002) showed that the PCC for children with SLI were $80.10 \%$ as compared to $87.67 \%$ for language-matched controls, and $98.69 \%$ for the age-matched controls. Thus, Hanna's problems in this area indicate a considerable delay. 
The PCCC measures indicated an even greater delay. At no point of observation did Hanna produce target clusters correctly. Her strategy was either to delete one or both consonants (e.g., ['patæ] for /'spadə/ 'shovel' and /æy/ for /stæjn/ 'stone'). At 9;4 she also produced some forms with two consonants, but with an epenthetic vowel between them, e.g., [po'lo] for /blo:/ 'blue', and [fæ'læk] for /flag/ 'flag'. These facts indicate that she mastered obstruent + sonorant clusters somewhat better than sibilant + stop clusters. In comparison, Kristoffersen \& Simonsen (2006) found in a study of the acquistion of word-initial two-element consonant clusters in normally developing 2- to 3-year-old children learning Norwegian that the PCCC for all clusters were 78\%. Moreover, obstruent + sonorant clusters were mastered significantly better $(81 \%)$ than sibilant + stop clusters (75\%). In other words, Hanna's performance was much poorer than typically developing children between 2 and 3 years of age. On the other hand, she followed the typically developing children in mastering obstruent + sonorant clusters better than sibilant + stop clusters.

Kristoffersen (2007b) also examined Hanna's various misarticulations in terms of three different types of articulatory errors earlier described within the theoretical framework known as Articulatory Phonology (see e.g. Browman \& Goldstein, 1989, 1992; Byrd, 2003; Studdert-Kennedy \& Goldstein, 2003): 1) errors of differentiation and tuning, 2) errors of coordination and sequencing, and 3) missing gestures. One of the questions addressed in this study was whether there was only persistence of errors in Hanna's speech, or whether there was also progress. The study demonstrated that Hanna made errors in all three categories. There were, however, some differences between the three categories. First of all, missing gestures amounted to more than $50 \%$ of all errors in the samples of her speech from the observation points at $4 ; 6,5 ; 9$, and 7;0. At 9;4, 
this type still made up a considerable share of all errors, but now only $44 \%$. At this point of observation, there were more errors of differentiation and tuning (49\% of all errors at this age). Thus, it seems safe to conclude that, evaluated on the basis of missing gestures, error patterns in Hanna's speech persisted. However, it was found that even though the share of missing gestures was high at all ages, there was still a significant between-group difference $(F=10.701 ; p=0.047)$. Posthoc analyses revealed significant differences between the amount of missing gestures at 4;6 on the one hand and at 7;0 and 9;4 on the other, between errors at 5;9 and 9;4, and between errors at 7;0 and 9;4. Thus, as far as missing gestures were concerned there were some amount of progress.

Also errors of differentiation and tuning were found to persist. There were 21 errors of this type at age $4 ; 6$ and 22 at age 9;4. In this case no significant differences between the four points of observation were found. In other words, for this error type there was persistence, but no progress.

At all points of observation there were few errors of coordination and sequencing. However, a significant decrease in the number of these errors was found between 4;6 and 5;9/7;0, once again indicating progress to some extent. In this category, there was a significant between-group difference $(F=2.728 ; p=0.000)$ between errors at the different points of observation. Post-hoc analyses showed significant differences between age $4 ; 6$ on the one hand, and ages $5 ; 9$ and $7 ; 0$ on the other.

Another finding of Kristoffersen (2007b) was that Hanna frequently omitted segments. For example, at age 4;6 there were 21 omissions in the word-initial position in the words selected for analysis. At age 9;4, the number of omissions had decreased to 
11. Also, there were differences relating to word position and age. At all four points of observation, she omitted segments in word-initial position more often than in word-final position. However, whereas at age 4;6 there were almost as many omitted segments word-finally as word-initially, at age 9;4 there were almost no omissions in word-final position, but still many omitted segments in word-initial-position.

All these results indicate that Hanna's language was extremely delayed. For example, the 2- to 3-year-old normally developing children who participated in the study reported on by Kristoffersen \& Simonsen (2006) omitted word-initial consonants in about $18 \%$ of the words. Moreover, Hanna's deletion patterns were also deviant in the sense that the most common pattern among typically developing children is omission of word-final consonants, whereas omission of word-initial consonants is uncommon (Small, 2005). This pattern of word-initial omissions persisted thorughout the period under investigation.

Even though Kristoffersen (2007b) presented a a large amount of details concerning consonant development in CCS, a number of issues still needs to be addressed within this area of language production. First, since this was a single-case study, the need for studies including more participants should be obvious. A problem here is of course the scarcity of persons with this syndrome. Furthermore, there appear to be extensive developmental variation among persons with CCS, and for that reason larger-scale group studies may appear to be impossible. An option is of course multicase studies.

Second, this study leaves the question unsettled as to what extent the articulation errors are relating to the phonological structure of Norwegian, and to what extent they 
can be ascribed to the delayed motor or cognitive development observed in persons with CCS. Here, investigations of other languages than Norwegian are needed, as well as studies of the relationship between speech and language, motor development, and nonverbal cognitive development.

\section{Vowels}

Kristoffersen (2003c, 2005) reported from an investigation of vowel productions in a small group of Norwegian children with CCS. The main findings were that for all the participants there was considerable variation in different attempts at producing the same target vowels, but to a varying extent depending on both vowel height and quantity. There was also extensive inter-subject differences. Furthermore, considerable acoustic overlap between attempts at producing different target vowels was registered. Finally, only to a limited extent did the vowel productions of the participating children form vowel spaces comparable to the vowel space of the target language, but as with consononant productions there was some inter-subject variability.

\section{Syllable shapes}

Kristoffersen (2003b) also reported on the development of syllable shapes produced by his daughter Hanna from age 4;6 to age 7;0. The target language (Urban East Norwegian) allows a range of different syllable types. First, in onsets words can have from zero to three consonants ( $i$ /i:/ 'in', strå /stro:/ 'straw'. Second, in polysyllabic words up to four consonants can occur intervocalically, e.g., mønstre /'mønstrə/ 'inspect'. Finally, in the syllable coda we find from zero to three consonants, e.g., blomst /blomst/ 'flower'.

In comparison Hanna's syllable shapes, as attested in Kristoffersen (2003b) were fewer and less complex, as table 6 shows. 


\begin{tabular}{lccc|lccc} 
Syll. shape/age & $4 ; 6$ & $5 ; 9$ & $7 ; 0$ & Syll. shape/age & $4 ; 6$ & $5 ; 9$ & $7 ; 0$ \\
\hline CV & 18 & 4 & 3 & CV.CV & 18 & 14 & 12 \\
V & 13 & 13 & 5 & V.V & 7 & 3 & 4 \\
VC & 1 & 9 & 16 & V.CV & 5 & 18 & 11 \\
CVC & 1 & 4 & 9 & V.CVC & 1 & - & 4 \\
\hline
\end{tabular}

By comparing the syllable shapes and their frequency at 5;9 with the corresponding shapes at 4;6 we see that the number of CV syllables decreased drastically, whereas the number of closed syllables increased. As for bisyllabic words, the number of CVCVsyllables decreased, and the number of V.CV-syllables increased.

At 7;0 the most striking property of the syllable shapes was that the number of closed syllables was more than doubled in comparison with 5;9 (29 to 13). Furthermore, the syllable shapes which are most typical of early phonologies - CV, V and CV.CV were drastically reduced, from 49 at $4 ; 6$, through 31 at 5;9, to 20 , at 7;0. In sum, whereas Hanna's phonetic inventory was relatively unchanged from $4 ; 6$ to $7 ; 0$, the way she organized these sounds into words was considerably changed.

\section{Summary}

In this section research on phonetic and phonological development in CCS was reviewed. The few studies that exist report a high fundamental frequency, frequent misarticulations, variable consonant and vowel productions that frequently misses the target, and syllable structures which are simpliefied in comparison to the target language. In the case of variable consonant and vowel productions the question arises whether these facts are a result of a more general problem of fine motor control, or if perception problems and poor ability to perceive the target of these productions also is a contributing factor.. This is a question that should be examined in future research.

An obvious weakness with the studies reveiwed in this section is that they are either case studies or include only a few participants. As this problem is a result of the scarcity of individuals suffering from this disorder, however, it is not easily remedied. 


\section{Morphology and syntax}

\section{Morphology: Inflection of nouns and verbs}

In a diary study ${ }^{3}$ of his daughter Hanna's expressive grammar between $4 ; 6$ and 7;0

Kristoffersen (2003d) found the following grammatical categories expressed (see table 7

for examples): Number and definiteness in nouns, aspect in verbs, gender and number in adjectives, and number in possessive prononuns.

Table 7. Nominal, verbal, pronominal and adjectival inflections in one case of CCS (Kristoffersen 2003d)

\begin{tabular}{|c|c|c|}
\hline & Target language & Hanna's speech \\
\hline \multicolumn{3}{|l|}{ Nouns - example bil 'car' } \\
\hline Singular indefinite 'car' & bil & bil \\
\hline Singular definite 'the car' & bilen & bilen \\
\hline Plural indefinite 'cars' & biler & bile \\
\hline Plural definite 'the cars' & bilene & \\
\hline \multicolumn{3}{|l|}{ Verbs - example spise 'eat' } \\
\hline Imperative 'eat!' & spis & pit \\
\hline Infinitive 'to eat' & spise & \multirow{3}{*}{ pite } \\
\hline Present 'eat(s)' & spiser & \\
\hline Past 'ate' & spiste & \\
\hline Perfect 'eaten' & spist & pit \\
\hline \multicolumn{3}{|l|}{ Adjectives - example $r \phi d$ 'red' } \\
\hline Masculine/feminine singular 'red' & $r \phi($ orthogr. $r \phi d)$ & $\phi$ \\
\hline Neuter singular 'red' & $r \phi t t$ (orthorgr. $r \phi d t)$ & $\phi t t$ \\
\hline Plural 'red' & $r \phi e$ (orthogr. $r \phi d e)$ & $\phi e$ \\
\hline \multicolumn{3}{|l|}{ Possessive pronouns - example min 'my' } \\
\hline Masculine/feminine singular 'my' & $\min$ & \multirow[t]{2}{*}{$\min$} \\
\hline Neuter singular 'my' & mitt & \\
\hline Plural 'my' & mine & mine \\
\hline
\end{tabular}

As table 7 demonstrates, Hanna inflected nouns for the same categories as those found in the target language - number and definiteness. For verbs an aspectual distinction (between 'imperative' and 'indicative') was found, whereas there were no signs of the temporal distinction in the target language between 'present' and 'past'. Furthermore, Hanna inflected adjectives for gender and number. In comparison, adjectives in the target

${ }^{3}$ Data for this study were collected in the following way: Throughout the period under investigation all inflected forms that were observed were registrered, transcribed and classified with resepct to the inflectional categories they expressed. 
language are also inflected for definiteness. Hanna's possessive pronouns were inflected for number, but not for gender. Against the background of these findings, a several of questions arise: The most obvious one is whether these findings generalize to other children with CCS? Another question is to what extent the inflected forms were rote learned or a result of productive schemas? Furthermore, one may ask what was the relationship between the particular forms and the frequency of the corresponding target forms?

Wium (2006; see also Wium \& Kristoffersen, 2007, for a summary in English of some of the results) compared the performance of 3 Norwegian subjects (aged 11, 15, and 22) with CCS on a past tense elicitation task, and found that all three subjects inflected verbs for past tense. Table 8 summarizes the results from this study and compares the performance of the three subjects with CCS with the perfomance on this test in other populations.

Table 8: Past tense production in CDCS as compared to other groups (Wium \& Kristoffersen, 2007)

\begin{tabular}{|l|c|c|c|c|c|c|c|}
\hline & P1 & P2 & P3 & $\begin{array}{c}\text { TD } \\
\text { Age } 4\end{array}$ & $\begin{array}{c}\text { TD } \\
\text { Age } 6\end{array}$ & $\begin{array}{c}\text { SLI age } \\
6.1-8.8\end{array}$ & Adults \\
\hline$\%$ Correct & $28 \%$ & $47 \%$ & $53 \%$ & $51 \%$ & $72 \%$ & $66 \%$ & $94 \%$ \\
\hline Gen $>$ WL & $7 \%$ & $25 \%$ & $54 \%$ & $44 \%$ & $52 \%$ & $29 \%$ & $10 \%$ \\
\hline Gen $>$ WS & $14 \%$ & $6 \%$ & $11 \%$ & $12 \%$ & $27 \%$ & $25 \%$ & $47 \%$ \\
\hline Gen $>$ S & $0 \%$ & $0 \%$ & $0 \%$ & $2 \%$ & $9 \%$ & $6 \%$ & $17 \%$ \\
\hline No change & $14 \%$ & $3 \%$ & $0 \%$ & $1 \%$ & $2 \%$ & $1 \%$ & $0 \%$ \\
\hline Imitation & $51 \%$ & $13 \%$ & $36 \%$ & $38 \%$ & $7 \%$ & $29 \%$ & $0 \%$ \\
\hline No response & $2 \%$ & $41 \%$ & $0 \%$ & $4 \%$ & $2 \%$ & $3 \%$ & $0 \%$ \\
\hline Wrong verb & $2 \%$ & $13 \%$ & $0 \%$ & $0 \%$ & $0 \%$ & $8 \%$ & $15 \%$ \\
\hline Other & $7 \%$ & $0 \%$ & $0 \%$ & $0 \%$ & $0 \%$ & $0 \%$ & $11 \%$ \\
\hline
\end{tabular}

Note 1: Norwegian verbs fall into several inflectional classes. There is a basic distinction between regular ("weak") and irregular ("strong") verbs. There are two main classes of regular verbs, one with a large number of members (WL), and one with considerably fewer members (WS). There are several classes of irregular ("strong") verbs (WS). In this table they are collapsed into one class. See Ragnarsdóttir, Simonsen, \& Plunkett (1999) for more details on the inflectional system of Norwegian verbs.

Note 2: TD data age 4 and age 8 are from Ragnarsdóttir, Simonsen, \& Plunkett (1999). SLI data and data from adults are from Bjerkan (2000). 
We see that the number of correct responses varied between subjects from $28 \%$ to $53 \%$, which is from well below to equal to the performance of typically developing 4-yearolds. Furthermore, the majority of errors made by the three subjects with CCS were overgeneralizations, imitation of input, no response, and substitution by semantically related verbs, errors which is also found in the other groups. Concerning overgeneralizations, we see that one subject (P1) have more overgeneralizations to the WS class than to the WL class, whereas the two others have more overgeneralizations to the WL class than to the WS class. The latter situation is also found with the TD children and SLI children, whereas the former situation is found with adults.

\section{Syntax: Word combinations}

In typically developing children the first two-word combinations appear at around 18 months of age. A few observations on word combinations can also be found in the literature on CCS. First of all, Sparks \& Hutchinson (1980) reported that their subject used two-word combinations at the age of three. Furthermore, when this girl was 7;6 old she mastered the following structures: pronoun+verb, article+noun, verb+object, prepositional phrases, adjective+noun. The following examples which illustrate some of these structures are given: help me, I go down, I love you, two black eyes, he is jumping. In other words, there were some signs of basic sentence structure and NP syntax in the language of the girl examined by Sparks \& Hutchinson (1980.

Second, Mainardi et al. (2000) reported on the emergence of two word combinations in 37 of their 84 partcipants. By four years of age $25 \%$ of them produced two-word combinations, by six years $50 \%$ of them did. Furthemore, $75 \%$ of the 8 -yearolds $95 \%$ of the 11-year-olds produced two-word combinations.

As was also the case within the studies focussing on morphology, we don't know to what extent the syntactic patterns observed are holophrases or rote learned patterns. Along with this question, it must be left to future research to address questions concerning the relationship between syntactic complexity and mean length of utterance. 


\section{Summary and conclusions}

This article has reviewed research on speech and language abilities in persons with cri du chat syndrome. Overall, there are few studies specifically examining issues related to speech, language and communication skills. The few that exist, however, point to the following general conclusions:

- not all persons with CCS are able to use spoken language as a means of communication

- their receptive language is generally better than expressive language

- their receptive and expressive vocabularies are small

- their articulation are characterized by omissions, distortions, and substitutions, their consonant inventories are small, their vowels are variable and overlapping, their syllable shapes are restricted as compared to those in the target language

- persons with CCS can inflect nouns, adjectives, verbs, and pronouns, but it is an open question to what extent this behaviour is the result of productive schemas and to what extent they are rote learned.

- some persons with CCS who communicate with spoken language express themselves in one-word utterances only, others use multi-word utterances

A general weakness with all the studies reviewed in this article relates to methodological issues (noted i.a. by Brock 2007). First of all, since the performance on tests by individuals with a genetic disorder is a result of several factors, of which their genetic factors constitute only one, case studies or small group studies do not necessarily tell us how much of this performance is a result of genetic factors, and how much is the result of other things, like environmental factors (including e.g. therapeutic intervention).

Furthermore, since there are so few individuals with rare syndroms like CCS the cohorts tend to include individuals within a considerable age range. It is possible that the cognitive profile assoeciated with CCS change with growing age, a situation which calls for caution in interpreting results

In all, it seems fair to conclude that we have too little and too little specific knowledge about language abilities in persons with CCS. The few studies that exist are 
either based on a few participants, or they restrict themselves to particular aspects of speech and language, leaving other areas untouched. In all areas discussed above more studies are necessary. In the domains of lexicon and syntax, there is virtually no research at all. In addition to broad and detailed descriptive studies within these domains there is also a need for MLU studies, for example on the relationship between syntactic complexity and MLU.

Another problem with previous studies is their lack of theoretical perspective. All the studies examined in this review are mainly descriptive, with very few references to theoretical work. At least the field of linguistics has seen an increasing demand for theoretically based studies, and this is something we should also expect from future research on language abilities and language development in cri du chat-syndrome.

Finally, more research on CCS will provide speech and language therapists with a firmer basis for developing intervention programs for improving comminications skills in individuals with CCS. However, with the appearance of such intervention programs the need for studies of effectiveness of these programs also arises.

\section{References}

Abbeduto, L., Brady, N., \& Kover, S. T. (2007). Language development and fragile X syndrome: Profiles, syndrome-specificity, and within-syndrome differences. Mental Retardation and Developmental Disabilities Research Reviews 13, 36-46.

Baird, S. M., Campbell, D., Ingram, R., \& Gomez, C. (2001). Young children with cridu-chat:: Genetic, developmental, and behavioral profiles. Infant-toddler intervention, $11,1-14$.

Bastiansee, R., Maas, E., \& Rispens, J. (2000). Werkwoorden-en Zinnentest (WEST). Lisse: Swets \& Zeitlinger.

Bastiansee, R., Edwards, S., Maas, E., \& Rispens, J. (2003). Assessing comprehension and production of verbs and sentences: The verb and sentence test (VAST). Aphasiology, 17, 40-73.

Bastiansee, R., Lind, M., Moen, I., \& Simonsen, H. G. (2006). Verb- og setningstesten (VOST). Oslo: Novus. 
Bishop, D. V. M. (1983). Test for the reception of grammar. London: Medical Research Council.

Bjerkan, K. M. (2000). Verbal morphology in specifically language impaired children. Evidence from Norwegian. Oslo: Unipub.

Brock, J. (2007). Language abilities in Williams syndrome: A critical review. Development and Psychopathology, 19, 97-127.

Browman, C. P., \& Goldstein, L. (1989). Articulatory gestures as phonological units. Phonology, 6, 201-251.

Browman, C.P., \& Goldstein, L. (1992). Articulatory phonology: An overview. Phonetica, 49, 155-180.

Byrd, D. (2003). Frontiers and challenges in articulatory phonology. In M. J. Solé, D. Recasens, \& J. Romero (Eds.), Proceedings from The 15th International Congress of Phonetic Sciences (pp. 89-92). Adelaide, Australia: Causal Productions Pty Ltd.

Carlin, M.E. (1990). The improved prognosis in Cri-du-chat (5p-) syndrome. In W.I. Fraser (Ed.), Key issues in mental retardation research. London: Routledge, pp 64-73.

Collins, M. S. R., \& Cornish, K. (2002). A survey of the prevalence of sterotypy, selfinjury and aggression in children and young adults with Cri du Chat syndrome. Journal of intellectual disability research, 46, 133-140.

Cornish, K., Bramble, D., \& Collins, M.S.R. (1998). Cri-du-chat syndrome. Guide lines for parents and professionals. Barwell: $\mathrm{Cr}$ du chat syndrome support group.

Cornish, K., Bramble, D., Munir, F., \& Pigram, J. (1999). Cognitive functioning in children with typical cri du chat (5p-) syndrome. Developmental medicine and child neurology, 41, 263-266.

Cornish, K., \& Munir, F. (1998). Receptive and expressive language skills in children with cri du chat syndrome. Journal of communication disorders, 31, 73-81. 
Cornish, K., \& Pigram, J. (1996). Developmental and behavioural characteristics of cri du chat syndrome. Archives of disease in childhood, 75, 448-450.

Dunn, L., Dunn, P., Whetton, C., \& Pintilie, D. (1982). British picture vocabulary scale. Windsor: NFER-Nelson.

Fenson, L., Dale, P., Reznick, S., Thal, D., Bates, E., \& Hartung, J. P. (1993). MacArthur communicative development inventories: Technical manual. San Diego, CA: Singular Publishing Group.

Gardner, M. F. (1990). Expressive one-word picture vocabulary-revised. California: Academic Therapy Publications.

Goldman, R., \& Fristoe, M. (1986). Goldman-Fristoe test of articulation. Minnesota, $\mathrm{MN}$ : American Guidance Service.

Grunwell, P. (1985). PACS. Phonological assessment of child speech. San Diego: College Hill Press.

Hansson, K., \& Nettelbladt, U. (2002) . Assessment of specific language impairment in Swedish. Logopedics Phoniatrics Vocology, 27, 146-154.

Higurashi, M., Oda, M., Iijima, K., Iijima, S., Takeshita, T, Watanabe, N., \& Woneyama, K. (1990). Livebirth prevalence and follow-up of malformation syndromes in 27.472 newborns. Brain development, 12, 770-773.

Hresko, W. P., Miguel, S. A., Sherbenou, R. J., \& Burton, S. D. (1994). Developmental Observation Checklist System: Examiner's manual. Austin, Tx: Pro-Ed.

Kristoffersen, K. E. (2003a). Development of consonants and vowels in a child with cri du chat syndrome. Journal of Multilingual Communication Disorders, 1, 194200.

Kristoffersen, K. E. (2003b). Phonological development in a child with cri du chat syndrome. Nordlyd [On-line serial], 31. ( HYPERLINK "http://www.ub.uit.no/baser/nordlyd/viewissue.php?id=3\#Articles" http://www.ub.uit.no/baser/nordlyd/viewissue.php?id=3\#Articles )

Kristoffersen, K. E. (2003c). Vowel production in cri du chat-syndrome - results from a case study. In M. J. Solé, D. Recasens and J. Romero (Eds.), Proceedings from 
The 15th International Congress of Phonetic Sciences (pp. 1663-1666). Adelaide, Australia: Causal Productions Pty Ltd.

Kristoffersen, K. E. (2003d). Expressions of grammar in Cri du chat syndrome - a case study. Developmental Medicine \& Child Neurology 45 (Suppl. 97), 47-47.

Kristoffersen, K. E. (2004). Consonant productions in three children with cri du chat syndrome. In B.E. Murdoch, J. Goozee, B.-M. Wehlan, \& K. Docking (Eds.), 2004 IALP Congress - Proceedings. Speech Pathology Australia.

Kristoffersen, K. E. (2005). Vowel productions in the speech of three children with cri du chat syndrome. Journal of Multilingual Communication Disorders, 3, 128-135.

Kristoffersen, K. E. (2007a). Norwegian speech acquisition. In S. McLeod (Ed.), The International Guide to Speech Acquisition. Thomson Delmar Learning.

Kristoffersen, K.E. (2007b). Consonants in Cri du chat syndrome: A case study. Journal of Communication Disorders (2007), doi:10.1016/j.jcomdis.2007.08.002

Kristoffersen, K.E., \& Simonsen, H. G. (2006) . The acquisition of \#/s/C clusters in Norwegian. Journal of Multilingual Communication Disorders, 4, 231-241.

Laczmanska, I., Stembalska, A., Gil, J., Czemarmazowicz, H., \& Sasiadek, M. (2006). Cri du chat syndrome determined by the 5 p15.3 $\rightarrow$ pter deletion-diagnostic problems. European Journal of Medical Genetics 49: 87-92.

Lee, S., Potamianos, A., \& Narayanan, S. (1999). Acoustics of children's speech: Developmental changes of temporal and spectral parameters. Journal of the Acoustic Society of America, 105, 1455-1468.

Lejeune, J., Lafourcade, J., Berger, R., Violette, J., Boeswillwald, M., Serginge, P., \& Turpin, R. (1963). Trois cais de délétion partielle du 13ras court d'un chromosome 5. Comptes Rendus de l'Academie des Sciences. Serie 111, Sciences de la Vie Pari, 257, 3098-3102.

MacLeod, S., van Doorn, J., \& Reed, V. A. (2001). Consonant cluster development in two-year-olds: General trends and individual difference. Journal of Speech, Language, and Hearing Research, 44, 1144-1171. 
Mainardi, P. C., Guala, A., Pastore, G, Pozzo, G., Bricarelli, F. D., \& Pierluigi, M. (2000). Psychomotor development in cri du chat syndrome. Clinical genetics, 57, $459-461$.

Medina, M., Mariescu, R. C., Overhauser, J., \& Kosik, K. S. (2000). Hemizygosity of (catenin (CTNND2) is associated with severe mental retardation in Cri-du-chatsyndrome. Genomics, 63, 157-164.

Mervis, C. B., \& Robinson, B. F. (2000). Expressive vocabulary ability of toddlers with Williams syndrome or Down syndrome: A comparison. Developmental Neuropsychology, 17, 111-126.

Mervis, C. B., \& Becerra, A. M. (2007). Language and communicative development in Williams syndrome. Mental Retardation and Developmental Disabilities Research Reviews, 13, 3-15.

Niebuhr, E. (1978). Cytologic observations in 35 individuals with 5p-karyotype. Human genetics, 42, $143-156$.

Oller, D. K, Eilers, R.E., Neal, R., \& Cobo-Lewis, A. (1998). Late onset canonical babbling: a possible early marker of abnormal development. Americal Journal of Mental Retardation, 103, 249-263.

Overhauser, J., Huang, X. G., Gersh, M., Wilson, W., McMahon, J., Bengtsson, U., Rojas, K., Meyer, M. \& Wasmuth, J. J. (1994). Molecular and phenotypic mapping of the short arm of chromosome-5 - sublocalization of the critical region for the cri-du-chat-syndrome. Human Molecular Genetics 3(2): 247-252.

Ragnarsdóttir, H., Simonsen, H. G., \& Plunkett, K. (1999). The acquisition of past tense morphology in Icelandic and Norwegian children. Journal of child language, 26, $577-618$

Reynell, J. K. (1985). Reynell developmental language scales. Windsor: NFER-Nelson.

Roberts, J. E., Price, J., \& Malkin, C. (2007). Language and communication development in down syndrome. Mental Retardation and Developmental Disabilities Research Reviews 13, 26-35.

Schlegel, R. J., Neu, R.L., Carneiro Leão, J, Reiss, J. A., Nolan, T. B., \& Gardner, L. I. (1967). Cri-du-chat syndrome in a 10 year old girl with deletion of the short arms of chromosome number 5. Helvetica paediatrica acta, 22, 2-12. 
Shriberg, L. D., \& Kwiatkowski, J. (1982). Phonological disorders 1: A Diagnostic Classification-System. Journal of Speech and Hearing Disorders, 47, 226-241.

Shriberg, L. D., Austin, D., Lewis, B. A., McSweeny, J. L., \& Wilson, D. L. (1997). The percentage of consonants correct (PCC) metric: Extensions and reliability data. Journal of Speech, Language, and Hearing Research, 40, 708-722.

Silber, D. L., Engel, E., \& Merrill, R. E. (1966). So-called 'Cri- du-Chat syndrome.' American journal of mental deficiency, 71, 486-491.

Simmons, A. D., Goodart, S. A., Gallardo, T. D., Overhauser, J. \& Lovett, M. (1995). 5 novel genes from the cri-du-chat critical region isolated by direct selection. Human Molecular Genetics, 4, 295-302.

Singer-Harris, N. G., Bellugi, U., Bates, E., Jones, W., \& Rossen, M. (1997). Contrasting profiles of language development in children with Williams and Down syndromes. Developmental Neuropsychology, 13, 345-370.

Smit, A. B. (1993). Phonologic error distributions in the Iowa-Nebraska articulation norms project: Word-initial consonant clusters. Journal of Speech and Hearing Research, 36, 931-947.

Smith, S. D. (2007). Genes, language development, and language disorders. Mental retardation and developmental disabilities research reviews, 13, 96-105.

Sohner, L., \& Mitchell, P. (1991). Phonatory and phonetic characteristics of prelinguistic vocal development in cri du chat syndrome. Journal of communication disorders, $24,13-20$.

Small, L. H. (2005): Fundamentals of Phonetics: A Practical Guide for Students. [2 ${ }^{\text {nd }}$ Ed]. Boston: Allyn and Bacon.

Sparks, S., \& Hutchinson, B. (1980). Cri du chat: Report of a case. Journal of communication disorders, 13, 9-13.

Studdert-Kennedy, M. \& Goldstein, L. (2003) . Launching language: Gestural origin of discrete infinity. In M. Christiansen, \& S. Kirby (Eds.), Language Evolution: The States of the Art (pp. 235-254). Oxford: Oxford University Press. 
Vicari, S., Caselli, M. C., Gagliardi, C., Tonucci, F., \& Volterra, V. (2002). Language acquisition in special populations: A comparison between Down and Williams syndromes. Neuropsychologia, 40, 2461-2470.

Warren, S.F. \& Abbeduto, L. (2007). Introduction to communication and language development and intervention. Mental retardation and developmental disabilities research reviews, 13, 1-2.

Wechsler, D. (1992). Wechsler intelligence scale for children (WISC-III). London: Psychological Corporation.

Wilkins, L. E., Brown, J. A., \& Wolf, B. (1980). Psychomotor development in 65 homereared children with cri-du-chat syndrome. The journal of pediatrics, 97, 401-405.

Wium, K. (2006). Preteritumsbøying og verbforståelse hos tre personer med cri du chatsyndrom. [Past tense inflection and verb comprehension in three persons with cri du chat-syndrome]. Master's thesis written at the University of Oslo (Department of Linguistics and Scandinavian Studies), URL HYPERLINK "http://wo.uio.no/as/WebObjects/theses.woa/wa/these?WORKID=42085" http://wo.uio.no/as/WebObjects/theses.woa/wa/these?WORKID=42085 .

Wium, K., \& Kristoffersen, K. E. (2007). Past tense morphology in Cri du chat syndrome: Experimental evidence. Manuscript submitted for publication.

Wu, Q., Niebuhr, E., Yang, H., \& Hansen, L. (2005). Determination of the 'critical region' for cat-like cry of Cri-du-chat syndrome and analysis of candidate genes by quantitative PCR. European Journal of Human Genetics, 13, 475-485. 